\title{
A SOLUÇÃO DE CONFLITOS CONSTITUCIONAIS ENTRE A LIBERDADE DE CRENÇA E DIREITO À VIDA: O CASO DAS TESTEMUNHAS DE JEOVÁ E A RALAÇÃO MÉDICO-PACIENTE.
}

\section{Deivison de Castro Rodrigues ${ }^{*}$}

\section{RESUMO}

$\mathrm{O}$ artigo apresenta o conflito entre a liberdade religiosa e o direito à vida, tendo como fundamento a utilização do princípio da proporcionalidade pelos tribunais superiores a fim de encontrar o ponto de equilíbrio e entre os princípios fundamentais colidentes. Ademais, demonstra o conflito e o impacto das decisões judiciais na solução do confronto entre a liberdade religiosa do paciente Testemunha de Jeová e o direito à vida. Expõe a relação médico-paciente e seu dever ético de salvar vidas. Ressalta a indisponibilidade do direito à vida e o quanto é essencial para o exercício das demais garantias fundamentais.

Palavras-Chaves: Liberdade religiosa; Direito à vida; Testemunhas de Jeová; Relação médico-paciente; Decisões Judiciais.

\section{THE SOLUTION OF CONSTITUTIONAL CONFLICTS BETWEEN FREEDOM OF BELIEF AND THE RIGHT TO LIFE: THE CASE OF JEHOVAH'S WITNESSES AND MEDICAL-PATIENT RALLY.}

\begin{abstract}
The article presents the conflict between religious freedom and the right to life, based on the use of the principle of proportionality by the higher courts in order to find the point of balance and between the fundamental principles colliding. In addition, it demonstrates the conflict and impact of judicial decisions in resolving the confrontation between the religious freedom of Jehovah's Witness patient and the right to life. It exposes the doctor-patient relationship and its ethical duty to save lives. It underscores the unavailability of the right to life and how essential it is for the exercise of other fundamental guarantees.
\end{abstract}

Key-words: Religious freedom; Right to life; Jehovah's Witnesses; Physician-patient relationship; Judicial Decisions.

\section{INTRODUÇÃO}

O direito e a medicina são ciências que se dedicam ao ser humano como objeto principal de seus estudos, especialmente em situações de conflito. Ademais, percebe-se que o vínculo mais intenso entre a medicina e o direito está na chamada relação médico-paciente e é nessa relação que tem surgido diversos desafios, dentre os quais encontramos a consciência

\footnotetext{
* Mestrando em Desenvolvimento Regional pela Universidade de Taubaté - SP. Especialista em Direito Previdenciário pela UNYLEYA, Graduado em Direito pela Faculdade Católica do Tocantins. Professor Universitário, vinculado ao curso de direito, desde 2016 na Universidade Estadual do Tocantins - UNITINS, Campus Dianópolis. Advogado constitucionalista e consultor jurídico.
} 
sobre a autonomia da vontade do paciente e a liberdade de crença religiosa, que tem ido de encontro ao direito a vida em determinados casos e, sabendo que são garantias constitucionais, questiona-se qual dessas garantias ou direitos fundamentais será melhor aplicado.

Esse posicionamento gera algumas indagações quanto à decisão dos pacientes com algumas debilidades, como por exemplo: poderia um doente com câncer recusar tratamento quimioterápico? Ou desistir de uma cirurgia radical como a amputação de um membro? Ou uma paciente católica devota que opta por não fazer um aborto, ainda que os médicos atestem que sua gravidez seja de alto risco? Seria possível um paciente islâmico renunciar o transplante de órgãos ou tecidos suínos como uma válvula cardíaca ou um fígado, mesmo que os médicos atestem um risco de morte? Seria aceitável um paciente Testemunha de Jeová optar por uma opção terapêutica isenta de sangue? Certamente são indagações que geram polêmicas e abordam questões médicas, jurídicas, éticas e principalmente geram a colisão de alguns dos direitos e garantias fundamentais.

Dentre essas indagações apresentadas a que mais tem se destacado são quanto aos pacientes Testemunhas de Jeová, aos quais não aceitam transfusões de sangue em virtude de crença religiosa. Existem opções terapêuticas isenta de sangue para alguns casos e em poucos hospitais no país. Essas formas seculares de tratamento tem sido um desafio para o desenvolvimento da medicina, os quais estão aprimorando métodos e técnicas com o intuito de apaziguar essa relação médico-paciente. Ademais, esse desenvolvimento também ocasionará a redução dos conflitos entre a autonomia da vontade do paciente, liberdade de crença religiosa e o direito à vida.

A pesquisa se propõe a discutir, explanar e tornar familiarizada determinada situação de conflito de direitos e garantias fundamentais, conflito esse que traz o seguinte questionamento: o que vale mais enquanto direito fundamental, o direito à vida ou a autonomia da vontade do paciente cominado com direito de crença religiosa?

Por ser o tema atual, que traz questões morais, culturais, jurídicas, éticas, religiosas e de direitos e garantias constitucionais, tem-se um estudo focado num conflito de valores da relação médico-paciente, onde de um lado está o paciente com sua aversão ao prognóstico médico, baseado em suas crenças e ideologias, ainda que contra a própria vida ou de seus representados. Do outro lado estão os médicos, com seu juramento de salvar vidas, impossibilitados de utilizar o tratamento mais eficaz para salvar o paciente, além de haver a 
possibilidade de sofrerem processo judicial caso venham a utilizar essas formas de tratamento sem o consentimento da outra parte ou de seus representantes.

Percebe-se que é um conflito de valores ético-religiosos, fundamentados em direitos e garantias constitucionais, porém, que vai de encontro a outra garantia constitucional, qual seja, direito à vida, defendido pelos médicos, razão pela qual se torna necessário conhecer esse conflito para que sejam averiguadas possibilidades de dissipá-los.

\section{DIREITO FUNDAMENTAL À VIDA E DIREITO FUNDAMENTAL À LIBERDADE RELIGIOSA}

No ordenamento jurídico, seguindo o liame dos direitos fundamentais, comumente escreve-se que não há hierarquia entre direitos fundamentais. Isso ocorre porque a constituição é una e como tal não poderia se sobrepujar a ela mesma seria ilógico, contudo, embora esse pensamento seja correto, há, por meios de critérios de valores, certa valoração quanto a alguns princípios.

Ademais, vale lembrar que o conceito de vida (previsto no caput do art. 5. ${ }^{\circ}$ da $\mathrm{CF}$, 88) é sobremodo complexo e para melhor entender a sua definição deve-se analisar o entendimento de José Afonso da Silva (2018, p.197) onde diz que: "Não intentaremos dar uma definição disto que se chama vida, porque é aqui que se corre o risco de ingressar no campo da metafísica supra-real, que não nos levará a nada".

Nesse entendimento Bulos (2018, p. 529) fala claramente que: “O direito à vida é o mais importante de todos os direitos”, ora, não existindo hierarquia entre leis constitucionais, como poderia a doutrina falar o contrário? Simples, cada norma constitucional possui um significado e cada valoração é dada conforme sua abrangência. Continua o autor:

\footnotetext{
"Seu significado [a vida] constitucional é amplo, porque ele se conecta com outros, a exemplo dos direitos à liberdade, à igualdade, à dignidade, à segurança, à propriedade, à alimentação, ao vestuário, ao lazer, à educação, à saúde, à habitação, à cidadania, aos valores sociais do trabalho e da livre iniciativa." (BULLOS, 2018, p. 529).
}

Ademais, entende-se que o direito à vida não só antecede as demais garantias constitucionais como também abrangem todas elas. Nesse sentido, Bonavides (2018, p. 391) apresenta que o art. $5^{\circ}$, caput da Constituição Federal o direito à vida está diretamente ligado à "dignidade da pessoa humana", que é um "valor supremo e um dos fundamentos da República Federativa do Brasil” (CF, art. 1. ${ }^{\circ}$ III, e art. 170). 
O entendimento do direito à vida não diz respeito apenas à questão biológica, isto é, a vida não consiste apenas em ter as funções psicomotoras em funcionamento, é algo mais amplo, e sobre essa questão em comento, Bonavides (2018, p. 392) entende que: “a proteção constitucional deve ser compreendida em uma dupla acepção: $1 .^{\circ}$ o direito de permanecer vivo; e, 2. o direito de uma existência digna".

Assim, sabendo-se que nenhum direito fundamental é absoluto e que, a determinar do caso concreto, determinada garantia será aplicada, nesse sentido Bonavides (2018, p. 292) entende que:

\begin{abstract}
"A 'inviolabilidade do direito à vida' não abrange toda e qualquer forma de existência, mas sim a vida humana com dignidade! A importância axiológica e o fato de ser pressuposto de todos os demais direitos conferem-lhe um peso elevado na ponderação, mas isso não significa um caráter absoluto. Além da hipótese de pena de morte em caso de guerra declarada, prevista expressamente no texto constitucional (CF, art. 5. ${ }^{\circ}$ XLVII, a), esta inviolabilidade poderá ser afastada nos casos de colisão, seja com o mesmo direito titularizado por terceiros (legítima defesa, estado de necessidade...), seja com outros valores constitucionalmente valorizados (aborto)."
\end{abstract}

Interessante notar que o posicionamento anterior apresenta o porquê do direito à vida possuir uma conotação elevada, em contrapartida também se constatou que embora essa elevação de valores exista, o direito à vida, igualmente às outras garantias fundamentais, estará sujeito ao caso concreto, ou seja, porque até o direito à vida não é absoluto.

Oriundo dos tempos mais primórdios do ser humano e existente nos dias atuais, as religiões possuem importante papel nas sociedades como mecanismo de freios dos instintos naturais e ordem do grupo social. Por meio dela se desenvolveu a identidade do ser humano, o respeito à natureza, à vida, à família, a Deus, contudo, inversamente proporcional, criou massas de pessoas ignorantes, abriu caminho para atrocidades, injustiças e usou o nome de Deus para justificar seus atos, tornando a religião um mal necessário, isto é, se por um lado ela pode ser manipuladora, por outro é por amor a ela que culturas de respeito, honestidade, caridade e projetos que buscam ajudar os necessitados têm sido disseminados.

Atualmente, como um processo de evolução legislativa das últimas décadas, viu-se garantir na Constituição Federativa do Brasil não uma, mas qualquer religião ou ausência dela, isto é, por ser um Estado laico desde 15/11/1889 (Proclamação da República), o mesmo não só passou a defender na $\mathrm{CF}$, de 1988 a escolha de qualquer religião, mas também a opção de escolher religião alguma, além de proibir o ensino religioso e o casamento religioso com efeitos civis (LENZA, 2018, p. 95). 
Nesse sentido, entende-se que o direito à liberdade religiosa descrita no art. 5. ${ }^{\circ}$, VI e VIII da CF, compreende da seguinte forma: "São invioláveis as liberdades de consciência, de religião e de convicção político-filosófica, cumprindo à lei proteger os locais onde as liturgias religiosas se realizam."

Dividindo o citado anteriormente em partes e explicando cada uma desses pontos, poder-se-á compreender o seu verdadeiro sentido de liberdade de consciência, de religião e de convicção.

$\mathrm{O}$ que se entende por liberdade de consciência é que ela é pressuposto para o exercício das demais liberdades do pensamento. Aqui se compreende o consciente, de pensar da forma que se desejar desde que não seja ilicitude. Ela consiste na adesão de determinados valores morais e espirituais sem levar em consideração aspecto religioso algum. A liberdade de crença é a possibilidade de crer em algo, ou ainda, de não crer em nada, como é o caso dos agnósticos e ateus. A liberdade de culto é uma forma de expressão da liberdade de crença, havendo possibilidades de serem exercidos em qualquer local, mesmo os templos tenham imunidade fiscal (CF, art. 150, VI, b). (AFONSO 2018, p. 242 - 250).

Essa abordagem reforça a ideia que toda liberdade religiosa necessita estar contida na liberdade de consciência, todavia, a liberdade de consciência não está vinculada à religião.

No entanto, todas essas abordagens estão sujeitas aos limites do Estado, nesse entendimento, de forma reflexiva à posição do Estado em relação a essa garantia fundamental tem sido questionada de diversas formas, uma delas, pode-se aludir Jayme Weingartner Neto (apud Cláudio da Silva Leiria, ano p. 120) traz a seguinte reflexão:

"O Estado deve levar a sério o fato de que a religião ocupa um lugar central na vida de muitas pessoas, devendo, portanto, 'consideração e respeito por todas as formas de religiosidade, mesmo pelas mais inconvencionais (...). O Estado tem, neste contexto, um dever de abster-se de perturbar; a adesão/abandono de uma confissão religiosa, a educação religiosa das crianças por seus pais ou responsáveis, o serviço religioso, o uso de indumentária própria ou de símbolos religiosos, etc. Trata-se de uma reserva de intimidade religiosa cujo mérito intrínseco é insindicável pelo Estado."

Assim, sabendo-se que o direito à vida não é absoluto, de igual modo a liberdade de consciência, crença e de culto também não será, ou seja, deve seguir suas tradições e culturas religiosas dentro dos limites legais. No entanto, o Estado não pode deixar sem amparo essas entidades religiosas, mas, em posição contrária, a Máquina Estatal visa garantias simétricas às liberdades religiosas. Ou seja, na justificativa de Paulo Bonavides (2018, p. 420) apresenta que: 
"Em um Estado secular, além da ausência de uma religião oficial, deve-se haver uma completa separação entre o Estado e a Igreja, transpondo-se o exercício do poder político para uma base não mais religiosa. Na esfera pública, só devem ser considerados argumentos seculares, pois 'o princípio do exercício do poder é neutro do ponto de vista das visões de mundo'. Por essa razão, os poderes públicos devem pautar suas condutas pela neutralidade religiosa, sendo inconstitucional a justificação de medidas fundadas exclusivamente em argumentos, princípios ou dogmas religiosos, os quais devem se manter restritos à consciência e às condutas individuais."

Desse modo, vê-se que o Estado tem que manter certa "distância" das religiões em respeito à laicidade, todavia, esse argumento não pode ser utilizado para justificar a sua inobservância em relação ao direito de liberdade de consciência, crença e de culto.

Para tanto, é importante identificar que a liberdade religiosa possui uma função de importante na sociedade, qual seja que ela tem influências positivas nas vidas das pessoas e que por isso o Estado deve protegê-la quando necessário. No entanto, o Estado também deverá fiscalizá-la para podar os excessos por ela gerados, como é o caso do fanatismo.

\section{OS TESTEMUNHAS DE JEOVÁ E AS TRANSFUSÕES SANGUÍNEAS}

Encontrado em mais de 235 países, presente no Brasil desde 1923, suas doutrinas, dentre outras, destacam-se: a crença na existência de somente Jeová, ou seja, desconsideram a existência da trindade, diferente como ocorre com a maioria das religiões cristãs; se alistam no exército, mas não são convocados por não participarem de guerras; não comemoram datas comemorativas em virtude possuírem uma origem, segundo eles, pagã, como por exemplo, o aniversário, natal, páscoa, dia dos namorados, etc.; outra doutrina que destaca essa crença das demais é que eles não aceitam transfusões de sangue ou de alguns de seus componentes com fundamentação no livro de Gênesis, 9:3-4; Levítico, 17:10 e Atos 15:19-21, ambos da Bíblia, onde proíbe que as pessoas se alimentem de sangue. (Associação Torre de Vigia de Bíblias e Tratados, 1996-2006).

Com enfoque na questão das transfusões sanguíneas e de seus componentes, mesmo que a fundamentação bíblica se refira a uma questão alimentar os Testemunhas de Jeová a entendem também de forma analógica, qual seja, quanto ao recebimento de sangue pela transfusão sanguínea.

Focando nos efeitos jurídicos vê-se que não há problema em respeitar essa aversão ao recebimento de sangue do paciente adepto a essa crença, isso se houver outra forma 
alternativa à transfusão sanguínea no caso de risco de morte. Nesse entendimento Marcelo Novelino (2018, p. 421) diz que:

"Quando existe uma forma alternativa de tratamento apta a ser utilizada na situação em concreto, não há dúvidas de que se deve respeitar o direito de escolha do paciente. O problema ocorre naqueles casos em que não há outra opção viável, diversa da transfusão de sangue, a ser utilizada para a manutenção da vida."

Visando encontrar uma forma menos gravosa para solucionar o caso em questão, seja no ponto de vista do paciente Testemunha de Jeová ou dos médicos, foram apresentados alguns aspectos que devem ser levados em consideração, quais sejam que em relação ao paciente dessa crença, a recusa de receber a transfusão de sangue, em momento algum poderá acarretar algum tipo de punição, embora o próprio direito à vida seja irrenunciável. O outro ponto apresentado, que diz respeito sobre a responsabilização dos médicos, estabelece que ao verificar as normas infraconstitucionais que as mesmas deverão ser interpretadas de forma que as obrigações que lhes são impostas deverão sobrepor-se a liberdade de escolha do paciente, de modo que essas normas não poderão imperar às da constituição (NOVELINO 2018, p. 421).

Quando houver uma questão de colisão de direitos fundamentais entre a irrenunciabilidade do direito à vida e a liberdade religiosa esse conflito deverá ser solucionado conforme a análise do caso concreto para se obter um resultado constitucionalmente esperado.

Para tanto, o autor apresentou algumas distinções que deverão ser feitas, quais sejam, primeiramente, quando se tratar de paciente absolutamente capaz e esteja consciente a ponto de expressar sua vontade, nesse caso há um entendimento de que não se poderia impor determinado tipo de tratamento, sendo que o médico deverá respeitar a autonomia da vontade do paciente, que é núcleo da dignidade da pessoa humana, e a liberdade de crença religiosa, ou seja, sem aplicar uma imposição externa de conduta imperativa. Entretanto, mesmo sabendo que o direito à vida compreende a dignidade da pessoa humana, isto é, o direito à vida digna, esse entendimento não é o seguido por alguns tribunais (NOVELINO 2018, p. 422).

A segunda distinção, segundo o autor acima, diz respeito aos pacientes que estão em estado inconsciente ou de incapacidade. Nestas hipóteses, não haveria possibilidade de substituir a vontade desse tipo de paciente pela dos pais ou responsáveis. Contudo, no caso de risco de morte, a transfusão de sangue deverá ser realizada, e, caso não ocorra, responderão 
concomitantemente pelos resultados dessa omissão os médicos envolvidos e os responsáveis ou familiares.

Nesse ponto encontramos uma colisão de direitos fundamentais, onde de um lado está o direito da autonomia da vontade do paciente cominado com o seu direito de crença religiosa prevista no artigo $5^{\circ}$ inciso VI e VIII da $\mathrm{CF}$, e do outro o posicionamento dos médicos em preservar a vida, independente de credo.

Há quem diga que a escusa da opção terapêutica da transfusão sanguínea seja um completo absurdo, sabendo que essa escolha pode resultar na morte do paciente. Entretanto, sabendo-se que um fundamento religioso não é bem aceito na sociedade em geral devido a lógica não coexistir em suas entrelinhas, principalmente quando ele está de encontro ao direito à vida, os Testemunhas de Jeová usam outra justificativa para fomentar a posição bíblica de que a transfusão de sangue seja impura, isto é, de que ela não é saudável.

De acordo com essa doutrina, estudos revelam que a transfusão de sangue possui os seus riscos a médio e longo prazo, por exemplo, segundo os Centros de Controle e Prevenção de Doenças (s.d., 2018), dos Estados Unidos da América, existe um momento que os anticorpos não identificam algumas doenças nos exames de sangue, esse momento é conhecido como "janela imunológica" onde doenças como o vírus do HIV são descritas da seguinte forma:

\footnotetext{
"Pode levar algum tempo para que o sistema imunológico produza anticorpos suficientes para serem detectados pelos testes de anticorpos, esse período pode variar de pessoa para pessoa. Esse período costuma ser chamado 'janela imunológica'. A maioria das pessoas desenvolvem anticorpos detectáveis entre duas e oito semanas (a média é 25 dias). Mesmo assim, é possível que alguns demorem ainda mais a desenvolver anticorpos detectáveis(...). Em casos bem raros, pode levar até 6 meses."
}

A questão da transmissão do HIV é apenas umas das doenças possíveis e segundo Wilson Ricardo Ligeira (2018, p. 02) poderá ser de duas categorias distintas:

"Os efeitos adversos das transfusões podem ser classificados em duas categorias: primeiro, as doenças infecciosas transmitidas pelo sangue ou hemoderivados; segundo, as chamadas reações transfusionais, que podem ser de natureza imunológicas, imediatas ou tardias, e não imunológicas, como reações febris ou reações hemolíticas."

A transfusão de sangue não é a melhor opção de salvar vidas, ante os prejuízos que ela pode causar, mas às vezes indispensável. A recusa dos pacientes Testemunhas de Jeová sobre a não aceitação de transfusões sanguíneas trouxeram um incentivo sobremodo elevado 
para que a medicina buscasse formas alternativas ao tratamento de transfusões sanguíneas, sendo que algumas formas já foram descobertas.

Por meio das formas alternativas à transfusão sanguínea, diversos tipos de cirurgias foram realizadas sem a utilização de sangue, quais sejam cirurgias de coração aberto, cirurgias ortopédicas, oncológicas, transplante de fígado, rim, coração e pulmão (LEIRIA 2018).

A utilização de técnicas que afastam a transfusão de sangue tem-se apresentado eficiente no sentido de evitar doenças, não de maneira completa e absoluta, pois em alguns casos a transfusão sanguínea ainda é indispensável, mas também no que diz respeito à proteção religiosa dos pacientes Testemunhas de Jeová.

Ademais, visando ajudar sua comunidade religiosa mundial, os Testemunhas de Jeová criaram uma organização internacional chamada COLIH (Comissões de Ligações com Hospitais- sigla em inglês), estando presente em 230 países e territórios, composto por médicos e advogados, eles ajudam na transferência de pacientes adeptos dessa religião com necessidade de transfusão de sangue para hospitais ou grupos de médicos que usam formas alternativas às transfusões sanguíneas, além de realizarem trabalhos de esclarecimento por meio de profissionais de saúde sobre essas formas de tratamento e também sobre os riscos das transfusões de sangue (LEIRIA).

No Brasil as Comissões de organizações com hospitais (COLIH) não estão tão efetivas como em outros países, entretanto tem atuado em hospitais brasileiros nas regiões mais desenvolvidas do país, dentre os quais pode-se citar o Hospital Nossa Senhora Conceição de Porto Alegre - RS (III Congresso Brasileiro de Bioética 2000).

Em nota, um grupo de membros da COLIH apresentou informações às Testemunhas de Jeová e a Sociedade Torre de Vigia alguns sucessos, insucessos e dúvidas sociais sobre as orientações da questão do sangue (Comissões de Ligações com Hospitais- sigla em inglês, s.d.). Em sentido positivo quanto as questões dos Testemunhas de Jeová há também elogios às inovações da medicina e seus avanços para substituir o sangue:

\footnotetext{
"Não podemos negar o fato de que os aparatos médicos, bem como os procedimentos e medicamentos tem se desenvolvido de forma impressionante. Isto tem sido o principal motivo para se reduzir a necessidade de produtos sanguíneos. Adicionalmente existem muitas empresas que desenvolveram produtos para incrementar a capacidade de coagulação e manter o volume sanguíneo no sistema circulatório. A terapia de Oxigênio Hiperbárico é outra ferramenta importante, ainda que muitos médicos recusem sua utilização, no entanto reconhecem seu valor no tratamento de anemia aguda." (COLIH, s.d.).
} 
As dúvidas e contradições apresentadas pela COLIH surgem quando se questiona a respeito da negação transfusão sanguínea e da aceitação de alguns componentes do sangue, contraposição que é expressa da seguinte maneira: O que é o sangue?

Utilizar as formas alternativas à transfusão de sangue é um mecanismo positivo de se evitar doenças, contudo, por ser uma área ainda objeto de pesquisa pela comunidade científica, principalmente nas instituições mantidas pelos Testemunhas de Jeová, ainda não foi possível substituir por completo os benefícios obtidos na utilização do sangue, conforme explicado pelos membros das Comissões de Ligações com Hospitais apresentaram a seguinte linha de raciocínio:

\footnotetext{
"Evitar a transfusão de sangue é uma forma de buscar tratamento médico de qualidade. Porém oferecer algo que possa substituir o sangue é impossível hoje em dia. Os médicos estão atentos a situação e a necessidade de algo que substitua as transfusões de sangue. Quando existir uma boa alternativa ao sangue os médicos usarão. As únicas reais alternativas hoje são as habilidades dos cirurgiões, alguns medicamentos, aparelhos e procedimentos técnicos disponíveis em alguns hospitais, e o risco de operar além dos limites críticos."(COLIH, s.d.).
}

Para evitar conflitos de garantias fundamentais um paciente Testemunha de Jeová tem diversos desafios para obter uma forma alternativa à transfusão sanguínea, dentre eles a dificuldade de encontrar um hospital ou médicos filiados às Comissões de Ligações Hospitalares, que essa forma alternativa tenha cobertura pelo Sistema Único de Saúde. Para aqueles que não podem fazer o tratamento em hospitais particulares ou filiados aos planos de saúde, a dificuldade tem sido encontrar profissionais que tenham domínio técnico-médico nos procedimentos de substituição do sangue nos hospitais públicos.

Entretanto, independente de qualquer contradição, sabendo-se que há pacientes que professam sua crença como o foco de sua vida, o que deve ser feito para salvá-las em caso de necessidade de transfusão sanguínea? É dever do Estado desenvolver políticas públicas para amparar os membros dessa religião, e com fundamento na a Constituição Federativa do Brasil, em seu artigo 196 é bem clara nesse sentido:"Art. 196. A saúde é direito de todos e dever do Estado, garantido mediante políticas sociais e econômicas que visem à redução do risco de doença e de outros agravos e ao acesso universal e igualitário às ações e serviços para sua promoção, proteção e recuperação."

Embora seja minoria, os adeptos dessa religião são pessoas que possuem, por parte do Estado, fundamentado no artigo $153, \S 1^{\circ} \mathrm{CF} / 88$, onde diz : "Todos são iguais perante a lei, sem distinção de sexo, raça, trabalho, credo religioso e convicções políticas", o direito de exigir um atendimento médico conforme suas convicções religiosas. 
Nesse sentido entende o professor José Afonso da Silva (2018, p. 216):

\begin{abstract}
“o princípio não pode ser entendido em sentido individualista, que não leve em conta as diferenças entre grupos. Quando se diz que o legislador não pode distinguir, isso não significa que a lei deva tratar todos abstratamente iguais, pois o tratamento igual não se dirige a pessoas integralmente iguais entre si, mas àquelas que são iguais sob os aspectos tomados em consideração pela norma, o que implica que os 'iguais' podem diferir totalmente sob outros aspectos ignorados ou considerados como irrelevantes pelo legislador".
\end{abstract}

Há também a argüição de que a própria Constituição Federal defende a objeção de consciência, que são pessoas que seguem algum princípio, moral ético ou de consciência que não é compatível com o serviço militar das forças armadas e por terem essa linha pacifista ou anti-militar, assim, a eles é imposta uma prestação alternativa, em tempos de paz, pela Constituição Federal de 1988, em seu artigo 143, § 1º. Logo, mais um motivo para que esse apelo de cobrança de meios de obter saúde seja dado pelo Estado.

Nesse sentido, foi decidido em favor de um paciente Testemunha de Jeová para que o SUS custeasse o tratamento alternativo à transfusão sanguínea em Estado diverso da Federação, por maioria, pela $5^{\text {a }}$ Câmara Cível do Tribunal de Justiça de Mato Grosso, no julgamento do Agravo de Instrumento n. ${ }^{\circ}$ 22395/2006, conforme o que se colaciona a seguir:

\begin{abstract}
"TESTEMUNHA DE JEOVÁ - PROCEDIMENTO CIRÚRGICO COM POSSIBILIDADE DE TRANSFUSÃO DE SANGUE - EXISTÃSNCIA DE TÉCNICA ALTERNATIVA - TRATAMENTO FORA DO DOMICÍLIO RECUSA DA ADMINISTRAÇÃO PÚBLICA - DIREITO À SAÚDE - DEVER DO ESTADO - RESPEITO À LIBERDADE RELIGIOSA - PRINCÍPIO DA ISONOMIA - OBRIGAÇÃO DE FAZER - LIMINAR CONCEDIDA - RECURSO PROVIDO. Havendo alternativa ao procedimento cirúrgico tradicional, não pode o Estado recusar o Tratamento Fora do Domicílio (TFD) quando ele se apresenta como a única via que vai ao encontro da crença religiosa do paciente. A liberdade de crença, consagrada no texto constitucional, não se resume à liberdade de culto, à manifestação exterior da fé do homem, mas também de orientar-se e seguir os princípios dela. Não cabe à administração pública avaliar e julgar valores religiosos, mas respeitá-los. A inclinação de religiosidade é direito de cada um, que deve ser precatado de todas as formas de discriminação. Se por motivos religiosos a transfusão de sangue apresenta-se como obstáculo intransponível à submissão do recorrente à cirurgia tradicional, deve o Estado disponibilizar recursos para que o procedimento se dê por meio de técnica que dispense-a, quando na unidade territorial não haja profissional credenciado a fazê-la. O princípio da isonomia não se opõe a uma diversa proteção das desigualdades naturais de cada um. Se o Sistema Único de Saúde do Mato Grosso não dispõe de profissional com domínio da técnica que afaste o risco de transfusão de sangue em cirurgia cardíaca, deve propiciar meios para que o procedimento se verifique fora do domicílio (TFD), preservando, tanto quanto possível, a crença religiosa do paciente.".
\end{abstract}

Esse caso diz respeito a pessoa de 60 anos de idade que havia ajuizado uma ação contra o Estado do Mato Grosso, na $3^{\text {a }}$ Vara da Fazenda Pública da comarca de Cuiabá, buscando por meio da justiça que o Estado custeasse a sua cirurgia cardíaca com métodos que 
ele não precisasse de receber transfusão sanguínea, passível de realização no Hospital Beneficência Portuguesa, na cidade de São Paulo/SP. Essa cirurgia poderia ter sido realizada no Estado em que reside, contudo, com a utilização de transfusão de sangue, o que vai de encontro às suas crenças religiosas.

Nesse sentido, é interessante saber, como foi o voto vencedor desse caso:

\begin{abstract}
"Para delimitar o âmbito deste apelo, impõe-se esclarecer que não se está a debater ética médica ou confrontação entre o direito à vida e o de liberdade de crença religiosa.O que se põe em relevo é o direito à saúde e a obrigação de o Estado proporcionar ao cidadão tratamento médico que não implique em esgarçamento à sua liberdade de crença religiosa.(...) O que incomoda-me bastante é a intransigência estatal em obrigar o recorrente a submeter-se a cirurgia que, pela técnica utilizada, ofenda os princípios religiosos dele.(...) Ora, a circunstância de o Estado ter em seus quadros um único profissional credenciado a fazer cirurgias cardíacas pelo SUS, que ainda não domina essas técnicas, pode impor ao paciente que submeta-se à cirurgia tradicional olvidando-se seus princípios religiosos? Não estaria o Estado, nessas condições, desrespeitando o direito à liberdade religiosa? Certo é que, tratando-se de cirurgia eletiva, o paciente com mal cardíaco submete-se a ela ou não, segundo a sua vontade. Este preceito transcende à ética médica e alcança a bioética, que tem como um dos princípios basilares o respeito aos valores, crenças e vontades do paciente. Ao lado do princípio hipocrático da benevolência, a bioética conclama o respeito à autonomia do paciente em anuir a este ou aquele procedimento médico, principalmente em face do Estado, quando movimentada por princípios religiosos.Se ao profissional da medicina impõe-se o dever de acatar a vontade do paciente, ainda que a medida ponha em risco a própria vida dele, que dizer então em relação ao Estado quando a recalcitrância funda-se em motivos financeiros?O que pretendo afirmar é que, havendo alternativa ao procedimento cirúrgico tradicional, não pode o Estado recusar o Tratamento Fora do Domicílio (TFD) quando se apresenta como a única via que vai ao encontro da crença religiosa do paciente.É preciso ter em mente que não se trata de capricho, teimosia ou intolerância do recorrente, mas de princípios religiosos, que proíbem a transfusão de sangue alogênico.Quase septuagenário, não quer ele arriscar a vida eterna pelos poucos anos de vida terrena. Diante da situação, afigura-se justo o Estado compeli-lo à escolha entre essas vidas?(...)Se por motivos religiosos a transfusão de sangue apresenta-se como obstáculo intransponível à submissão do recorrente à cirurgia tradicional, deve o Estado disponibilizar recursos para que o procedimento se dê por meio de técnica que dispense-a, quando na unidade territorial não haja profissional credenciado a fazê-la."
\end{abstract}

Com base nesse voto, o relator pretende que a máquina administrativa busque desenvolver e aplicar medidas de saúde pública que alcance todas as pessoas, inclusive aquelas que se abstém de determinado procedimento por convicções religiosas, como é o caso dos Testemunhas de Jeová, assim, suprir a deficiência do SUS quanto à utilização de procedimentos alternativos às transfusões de sangue é indiscutivelmente necessário.

Não são todos os casos que possuem possibilidades de se buscar uma forma alternativa à transfusão sanguínea, dentre esses casos, os que têm se destacado sobre os demais são aqueles em que crianças e adolescentes estão envolvidos. É nesse ponto em que posicionamentos de tribunais brasileiros têm mantido um entendimento linear. 
Na hipótese de menor impúbere, se houver possibilidade de salvaguardar a vida do menor com meios e procedimentos que substituam a aplicação do procedimento de transfusão de sangue, então, a vontade religiosa deverá prevalecer e ser aplicado a respectiva forma alternativa.

Essas são situações problemáticas oriundas da laicidade do Estado que colocam em contrapartida a liberdade religiosa com a intervenção estatal. Para que haja um equilíbrio é necessário que a liberdade religiosa aja dento da razoabilidade e proporcionalidade, caso contrário, o Estado protegerá o bem jurídico fundamental, basilar e requisito para as demais garantias fundamentais que é o direito à vida, além disso, essa intervenção estatal pode ser vista como uma forma de preservar a garantia da ordem pública.

Em conflitos de direitos fundamentais não existe um pólo errado e outro certo, mas sim que um deles possui não apenas uma valoração mais elevada, mas que o de maior valor conduzirá a um resultado mais vantajoso, no caso dos pacientes Testemunhas de Jeová e sua recusa de transfusões sanguíneas em contrapartida ao direito à vida, essa garantia fundamental de maior valor será, sem dúvida, o direito fundamental à vida, garantia basilar indisponível.

O sangue é um elemento essencial à vida, seja ele num sentido biológico, para o funcionamento do corpo, ou como em seu valor espiritual para algumas religiões. Todavia, independente do valor que for atribuído a esse componente do corpo humano, de modo algum ele poderá deter tamanho significado que transpasse o valor supremo da existência, qual seja o de viver dignamente.

Havendo algum perigo de vida cabe ao médico tomar todas as decisões necessárias para o sustento da vida do paciente. Logo, na recusa do paciente quanto ao recebimento de transfusão de sangue, percebe-se que deve, antes de qualquer coisa, ser analisada a efetiva existência da necessidade do ato, ou seja, se o ato for definitivamente necessário para conservação da vida do paciente, deve ser efetivado, ainda que com sua expressa recusa ou de seus representantes. Se o ato for tão somente útil ou conveniente, a vontade do paciente será acatada, evitando assim, a realização da transfusão sanguínea.

Esse entendimento reflete a aplicação do princípio da proporcionalidade ao caso dos Testemunhas de Jeová, isto é, de forma clara percebe-se o momento em que a vontade do paciente adepto desse crença será desconsiderada, em favor da vida, e quando não interferir no direito de viver será respeitada o direito a liberdade religiosa. 
Em entendimento contrário, Leiria (2018) entende que os motivos que levam a classe médica e hospitais a preferir salvar vidas em detrimento à liberdade religiosa não está apenas na ponderação de valores, mas no temor a demandas judiciais e administrativas, sustentadas na legislação Penal brasileira e nas normas e regulamentos do Conselho Regional de Medicina (CRM).

Sabe-se que quando os médicos atuam sob o respaldo técnico-científico para salvar a vida dos pacientes entende-se que os mesmos, ao desrespeitarem a recusa de transfusão de sangue de pacientes Testemunhas de Jeová, estarão acobertados por uma excludente de ilicitude, ou seja, como leciona Carlos Ernani Constantino (1997, p. 11) em seu artigo sobre Omissão de socorro, o mesmo alui que:

\begin{abstract}
“(...) se o médico, em razão da crença de seu paciente ou de familiares deste, deixar de ministrar uma transfusão de sangue, quando necessária, cometerá o crime de omissão de socorro (art. 135 do CP); e que, se os familiares do enfermo ou acidentado incentivarem o médico a tal conduta omissiva serão partícipes do seu delito, nos termos do art. 29 do CP. Sustentamos, de outro lado, que, se, nas situações acima referidas, o profissional da medicina fizer a transfusão de sangue, mesmo contra a vontade de seu paciente ou de seus representantes legais, aplicando um sedativo à pessoa em tratamento, se necessário, não cometerá constrangimento ilegal (art. 146 do CP), pois não configura este delito "a intervenção médica ou cirúrgica, sem o consentimento do paciente ou de seu representante legal, se justificada por iminente perigo de vida" (inc. I do $\S 3^{\circ}$ do art. 146). Mas, se não houver iminente perigo de vida ou de saúde, deve-se respeitar o pensamento religioso do paciente.".
\end{abstract}

A previsão legal para que o médico atue contra a vontade do paciente ou seus representantes, quando houver risco de morte, também estão previsto no artigo 146, $\S 3$, inciso I, do Código Penal Brasileiro: "A intervenção médica ou cirúrgica sem o consentimento do paciente ou de seu representante legal, se justifica por iminente perigo de vida".

Posteriormente, se um paciente Testemunha de Jeová, tiver sua vida salva por uma transfusão de sangue e vier a demandar judicialmente contra o médico que realizou o procedimento, este estará resguardado sob as asas da lei, e nesse sentido, segundo o Recurso de Apelação à $3^{\text {a }}$ Câmara de Direito Privado de São Paulo SP tem sido o posicionado em casos de indenização por violação de preceito religioso:

"EMENTA: Indenizatória Reparação de danos Testemunha de Jeová Recebimento de transfusão de sangue quando de sua internação Convicções religiosas que não podem, prevalecer perante o bem maior tutelado peta Constituição federal que é a vida Conduta dos médicos, por outro lado, que pautou-se dentro da lei e ética profissional, posto que somente efetuaram as transfusões sangüíneas após esgotados todos os tratamentos alternativos Inexistência, ademais, de recusa expressa a receber transfusão de sangue quando da internação da autora Ressarcimento, por outro lado, 
de despesas efetuados com exames médicos, entre outras, que não merece acolhido, posto não terem sido os valores despendidos pela apelante Recurso improvido. (Apelação com Revisão $12343044003^{\mathrm{a}}$ Câmara de Direito Privado do TJSP Relator Des. Flavio Pinheiro data do registro 18.06.2002).”

Em regra, esse tem sido o entendimento jurisprudencial em relação ao médico e à sua opção de não deixar realizar e aplicar tratamentos eficientes para preservar a vida de pacientes Testemunhas de Jeová, vale lembrar que isso só ocorre quando não houver outras formas de salvaguardar a vida desses pacientes por meios de métodos alternativos.

Ademais, por não haver posicionamento do Supremo Tribunal Federal (STF) para dizer sobre a constitucionalidade da recusa de transfusão de sangue em pacientes Testemunhas de Jeová, segundo Luiz Lopes de Souza Jr. (2018) atualmente existem duas correntes doutrinárias para tratar do assunto.

A primeira corrente doutrinária é baseada na dignidade da pessoa humana e do princípio da liberdade de consciência e crença, essa corrente diz que a vontade do paciente deve ser respeitada. Vale lembrar que os pais ou responsáveis não podem decidir sobre menores, ou seja, ninguém pode dispor sobre o direito de personalidade de outra pessoa.

A segunda corrente doutrinária baseia-se no princípio da proporcionalidade, defende que o direito à vida é uma garantia fundamental indisponível, o que justifica a intervenção médica. Em regra, essa corrente prevalece na jurisprudência.

Assim, é uma questão de tempo para que a corte maior se manifestem, sobre o conflito, uma vez que a recusa de sangue dos pacientes Testemunhas de Jeová tem crescido de tal forma que não há como não dar relevância ao tema.

Enquanto esse entendimento não é pacificado, as decisões majoritárias estarão sob a luz do princípio da proporcionalidade, buscando preservar a vida do paciente dessa crença quando estiver em risco de morte e fizer valer sua vontade quando a transfusão de sangue for tão somente necessária.

Por fim, entende-se que sem vida não há dignidade, liberdade, crença, religião, convicção, não há nada. E por ter valor fundamental indisponível e absoluto, qualquer conduta que buscar a sua preservação terá amparo constitucional.

\section{CONCLUSÃO}

A colisão de direitos e garantias fundamentais entre a liberdade religiosa e o direito à vida será solucionado tão somente por meio da aplicação do princípio da 
proporcionalidade/razoabilidade ao caso concreto. Sua aplicação implicará num resultado menos gravoso, ou seja, em regra, o princípio da proporcionalidade, em detrimento do direito à liberdade religiosa, sobreporá o direito à vida ao caso com o fundamento de que a vida é preceito fundamental basilar para a aplicação dos demais direitos fundamentais, além de ser garantia fundamental indisponível.

A proporcionalidade, no que diz aos seus efeitos, possui aplicabilidade que atinge todas as pessoas, além de se encaixar perfeitamente entre os meios e determinados fins. Evitando a violação desse princípio, na visão de Gentz (apud Paulo Bonavides, 2018, p. 393) ele entende que a proporcionalidade busca o "controle do excesso", na relação entre o meio e o fim, quando for confrontando o "fim e o fundamento de uma intervenção com seus efeitos", isto é, quando houver excesso, desproporcionalidade e desequilíbrio entre os meios e os fins pretendidos esse princípio será aplicado para se instituir o devido equilíbrio.

O direito a vida e à liberdade religiosa são igualmente tutelados pela Constituição da República Federativa do Brasil, norma hierarquicamente superior às demais e que molda todo o ordenamento jurídico, seja por suas próprias regras, seja pelos princípios gerais do direito ao qual se inspira.

Num sentido reflexivo, nota-se quão grande e complexa é a análise de uma colisão autêntica, sobretudo no que diz respeito aos seus efeitos, que embora seja o resultado menos gravoso, contudo, sempre acarretará em um peso sobremodo elevado no campo dos direitos e garantias fundamentais, qual seja a aplicação de uma garantia fundamental em detrimento de outra, no caso em que estas estiverem em conflito.

De maneira explícita entende ser importante questionar: quais seriam as possibilidades de solução em caso de conflito entre a liberdade de crença religiosa (art. 5. ${ }^{\circ}, \mathrm{VI}$ e VIII da $\mathrm{CF} / 88$ ) e o direito à vida (art. $5^{\circ}$, caput da $\left.\mathrm{CF} / 88\right)$ ?

O pensamento mais comum que vem à mente para solucionar esse tipo de conflito é tentar saber qual deles é hierarquicamente superior. Todavia, embora a constituição seja una, não incorre em erro identificar diferentes pesos no universo dos direitos e garantias fundamentais, vale lembrar que esses pesos são um reflexo do significado constitucional de cada preceito fundamental.

Visando uma regra geral para solucionar caso em comento During (apud Mendes; Martins; Gonet 2018, p. 423) apresentou a seguinte fórmula: “valores relativos às pessoas têm 
precedência sobre valores sobre índole material", ou seja, as garantias constitucionais que estão ligadas diretamente ao agente de direitos terão certo peso sobre as demais.

Ressalta que a ligação das garantias fundamentais com o indivíduo são aquelas que procuram a defesa de valores conscienciosos e biológicos, ademais, ainda que esse critério de verificação de atribuição de peso constitucional busque certa solução de conflito de garantias fundamentais, todavia, não solucionaria a questão alvitrada, pois ambas garantias em colisão constituem-se dos valores relativos às pessoas.

Então, como haveria de ser solucionado esse conflito entre liberdade religiosa e direito à vida? Essa resposta encontra-se no princípio da proporcionalidade/razoabilidade (princípio de ponderação de direitos e garantias fundamentais), operada em três planos, da intensidade da intervenção, dos seus fundamentos e sua realização (Alexy Robert apud Mendes; Coelho; Branco 2018).

Isto é, na colisão de conflitos fundamentais, os critérios de aplicação deverão seguir esse critério de ponderação, sabendo-se que o último deles, proporcionalidade em sentido estrito, está reservado para dirimir conflitos em que haverá a aplicação determinada garantia fundamental em detrimento de outra, como é o caso do direito à liberdade religiosa em oposição à vida.

Igualmente, percebendo que grande parte da doutrina defende que a vida é um bem muito maior e mais valoroso que as demais garantias e que ela é fonte basilar para a aquisição de outros direitos, logo, nota-se que o direito à vida se sobrepõe a todos os demais direitos e garantias.

Nos casos em que existir possibilidades de substituição da transfusão sanguínea por tratamentos alternativos a vontade do paciente deverá ser respeitada, isto é, havendo formas de preservar a vida e a integridade religiosa do paciente adepto da religião Testemunhas de Jeová, logo, deverão ser observadas para que possam coexistir o direito à vida e a liberdade religiosa concomitantemente no caso concreto.

Há por meio desse estudo, não só o conhecimento do conflito entre a liberdade religiosa do paciente Testemunha de Jeová e o direito à vida, mas também que por meio dessa relação conflituosa entre médicos, hospitais e pais ou representantes de pacientes dessa religião em comento pode-se compreender a amplitude e abrangência do direito à vida, a dependência das outras garantias fundamentais a este e o porquê que esse direito, em regra, sobrepujou os demais. 


\section{REFERÊNCIA}

BARROSO, Luís Roberto. Curso de Direito Constitucional Contemporâneo. $7 .^{\text {a }}$ ed., São Paulo: Saraiva, 2018.

BONAVIDES, Paulo. Curso de Direito Constitucional. 33. a ed., São Paulo: Malheiros, 2018.

BRASIL. Código Penal (1940). Código Penal Brasileiro: promulgado em 07 de dezembro de 1940. Organização do texto: Antônio Luís de Toledo Pinto et al. 56. ${ }^{a}$ Ed. São Paulo: Saraiva, Vade Mecum, 2018.

Constituição (1988). Constituição da República Federativa do Brasil: promulgada em 5 de outubro de 1988. Organização do texto: Antônio Luís de Toledo Pinto et al. 56. ${ }^{\mathrm{a}}$ Ed. São Paulo: Saraiva, Vade Mecum, 2018.

BULOS, Uadi Lammêgo. Curso de Direito Constitucional. 11. a ed., São Paulo: Saraiva, 2018.

COMISSÕES DE LIGAÇÕES COM HOSPITAIS (COLIH), s.d., p. 01. Disponível em: http://kaique-10.sites.uol.com.br/cartaCOLIH.html. Acesso em: 16 de Nov. 2018.

CONSTANTINO, Carlos Ernani. Transfusão de Sangue e Omissão de Socorro. Revista Jurídica da Síntese, no 241, págs. 57/59, e no Jornal Tribuna do Advogado, edição de outubro/novembro de 1997, pág. 11 . Disponível em: http://lc4.in/Yls3. Acesso em: 10 de Nov. de 2018.

DÉCIMA PRIMEIRA CÂMARA CÍVEL DO TJRS, relator Cláudio Mello Tavares, julgado em 27/06/2007, Agravo de Instrumento: n. ${ }^{\circ}$ 2007.002.09293 RS. Disponível em: http://www.tj.rj.gov.br/institucional/dir_gerais/dgcon/pdf/jurisprudencia/selecao/outros/transf usao_sangue.pdf. Acesso em 12 de outubro de 2018.

III CONGRESSO BRASILEIRO DE BIOÉTICA, 3 e 4., 2000, Porto Alegre - RS. Disponível em: http://www.ufrgs.br/bioetica/conres.htm\#44 . Acesso em: 16 de Nov. 2018.

LEIRIA, Cláudio da Silva. Transfusões de sangue contra a vontade de paciente da religião Testemunhas de Jeová: uma gravíssima violação dos direitos humanos. Revista jurídica Jus Vigilantibus, sábado, 18 de abril de 2009. Disponível em: http://jusvi.com/artigos/39291/1. Acesso em 12 de novembro de 2018.

LEITÃO, Matheus. Estado do Rio dá a Religiosos o direito de recusar transfusão. Folha de São Paulo, São Paulo, 27/04/2010, Saúde, p. 1. Disponível em: http://www1.folha.uol.com.br/fsp/saude/sd2704201001.htm. Acesso em 20 de nov de 2018. 
LIGIERA, Wilson Ricardo. Tutelas de urgência na recusa de transfusão de sangue. Jus Navigandi, Teresina, ano 14, n. 2221, 31 jul. 2009. Disponível em: http://lc4.in/9jD1. Acesso em: 16 nov 2018.

MENDES, Gilmar Ferreira. Direitos Fundamentais e Controle de Constitucionalidade: Estudos de Direito Constitucional. rev., amp., 4. ${ }^{a}$ ed., São Paulo: Celso Bastos Editor, 2012.

NOVELINO, Marcelo, Curso de Direito Constitucional, rev., atual., amp., 2018, editora Juspodivm, 13. ${ }^{\mathrm{a}}$ ed.

QUE DEUS QUER DE NÓS?. Cesário Lange - SP: Associação Torre de Vigia de Bíblias e Tratados, 1996-2006-.

ROLIM, Luciano Sampaio Gomes. Colisão de direitos fundamentais e princípio da proporcionalidade. Jus Navigandi, Teresina, ano 06, n. ${ }^{\circ}$ 56, abr. 2002. Disponível em: http://www1.jus.com.br/doutrina/texto.as p?id=2855. Acesso em 08 de outubro de 2010.

S.n., Sangue submetido ao teste de HIV é seguro?. Página oficial da Torre de Vigia. Junho de 2008, s.l. Disponível em: http://www.watchtower.org/t/200806a/article_01.htm. Acesso em 11 de outubro de 2018.

SEXTA CÂMARA CÍVEL DO TJRS, relator Sérgio Gisthkow Pereira, julgado em 28/03/1995, Apelação Cível: AC 595000373 RS, TRANSFUSÃO DE SENGUE-TJRS Apelação Cível: AC 595000373 RS. Disponível em: http://lc4.in/Xs95. Acesso em: 21/09/2018.

SILVA, José Afonso da. Curso de direito constitucional positivo. 41. ed. rev. e atual. nos termos da reforma constitucional. São Paulo: Malheiros, 2018.

SOUZA, JR Luiz Lopes de. A dignidade da pessoa humana e os direitos fundamentais: princípio ou direito absoluto? LFG, 2009. Disponível em :

www.lfg.com.br/public_html/article.php?story=2009073140140365. Acesso em 18 de nov de 2018 .

TERCEIRA CÂMARA DE DIREITO PRIVADO DO TJSP, relator Flávio Pinheiro, julgado em 07 de maio de 2002, Apelação Cível: n. ${ }^{\circ}$ 123.439-4 SP. Disponível em:

http://www.tj.rj.gov.br/institucional/dir_gerais/dgcon/pdf/jurisprudencia/selecao/outros/transf usao_sangue.pdf. Acesso em 12 de outubro de 2018. 